HUMANIKA Vol. 19 No. 1 (2014) ISSN 1412-9418

Binner Ethical Ajaran Sosrokartono

Mulyono

\title{
BINNER ETHICAL AJARAN SOSROKARTONO DALAM PERSPEKTIF HERMENEUTIKA
}

\author{
Mulyono \\ Fakultas Ilmu Budaya Universitas Diponegoro \\ J1. Prof. H. Soedarto, SH Tembalang Semarang 50275 \\ Email: mulisti55@yahoo.co.id
}

\begin{abstract}
This paper seeks to interpret and seek relevance of Sosrokartono's moral teachings, especially those expressed in the binner ethical form, for the life of Indonesian people in the present. Binner ethical in the moral teaching is discovered in Javanese culture. To be able understand the moral teaching need interpretation in depth, not only use ability to reason but also the using ability of "rasa-pangrasa". The Sosrokartono's binner ethical, as well as other moral teachings, still based on Sosrokartono's philosophy of life that emphasized the obligation of human life to serve and devote themselves to God Almighty trough the help and helping fellow humans in need without strings attached, on the basis of principle "leladi mring sesami”. The Sosrokartono's moral teachings have relevance for the formation of Indonesian national character, which is currently demoralized. The Sosrokartono's moral teachings are very concerned with inner strength to counteract the development of the character of individualistic, materialistic, hedonistic and secularistic on Indonesian peoples, which currently is beset by modernization and globalization.
\end{abstract}

Key words: moral teaching, binner ethical, interpretation, relevance, counteract, modernization and globalization, Indonesian national character

\section{PENDAHULUAN}

Pengertian binner etichal dalam tulisan ini adalah ajaran kongkret tentang perilaku manusia yang baik dengan mengunakan dua kata yang saling berlawanan. Dua kata yang berlawa-nan ini dicoba dipadukan dengan memasukkan citra positif ke dalam citra negatif, agar citra negatif terkontaminasi citra positif, sehingga yang tampak dan dirasakan oleh indera adalah citra positifnya. Ajaran moral yang berbentuk binner etichalsemacam ini tidak pernah diketemu-kan dalam pemikiran dan kebudaya-an Barat yang lazimnya bersifat rasionalistik. Binner etichal hanya bisa diketemukan pada 
pemikiran dan kebudayaan Timur, khususnya Jawa, karena untuk memahami ajaran itu tidak hanya diperlukan kemampuan indera dan akal namun juga harus menggunakan ñrasaPangrasaò. Pengungkapan binner etichal sering mengunakan logika paradoksal.

Jika pemikiran dan ajaran Sosrokartono begitu luas bidangnya tentang kehidupan manusia, maka ajaran Sosrokartono yang paling dikenal dan berpengaruh pada masyarakat adalah dalam bidang moral. Sedangkan sebagian dari ajaran moral Sosrokartono diungkap-kan dalam bentuk binner etichal. Pemikiran Sosrokartono, yang terungkap dalam berbagai mutiara sabda maupun tulisan-tulisannya, kaya akan ajaran moral. Ajaran-ajaran moral tersebut memberikan piwulang tentang manusia yang baik dan bagaimanakah seharusnya manusia berbuat dalam kehidupannya menghadapi orang lain, alam semesta, maupun Tuhan.Sosrokartono bukanlah person yang hanya melahirkan pemikiran dan ajaran yang bersifat teoritis belaka, melainkan ia mempraktikkan apa yang diajarkan itu ke dalam perilaku sehari-hari secara konsisten. Ki Musa Al Machfoeld (1976: 2) menyebutkan bahwa Sosrokartono memiliki ajaran yang metodis dan didaktis seperti diajarkan oleh para Wali dan para Auliya, serta mengamalkan ibadahnya dengan jalan ñFilisaanil haalò, artinya tidak hanya dengan kata-kata akan tetapi dengan bahasa contoh perilaku.Ajaran moral
Sosrokartono meletakkan motif dasar yang menggerakkan suatu perbuatan pada rasa wajib manusia untuk bertaqwa dan menghambakan diri kepada Tuhan sebagai Al Khalik. Kewajiban bagi manusia adalah mencintai dan mengabdi kepada Tuhan. Bentuk kongkret dari kewajiban itu adalah mencintai dan mengabdi pada sesama makhluk Tuhan, yang seharusnya dimanifestasikan pada berbuat leladi mring sesami, menolong sesama manusia yang membutuhkan pertolongan. Sedangkan perbuatan atau tindakan itu dilakukan tanpa pamrih dan semata-mata karena rasa wajibnya untuk mencintai dan mengabdi kepada Tuhan. Ajaran moral Sosrokartono menjadi warisan nilai-nilai akhlak yang mengandung hikmah besar sekali bagi nation and character building di Indonesia (Ali, 1966: 14).

Ajaran moral Sosrokartono mempunyai relevansi yang tinggi untuk menjawab persoalan yang dihadapi bangsa Indonesia saat ini, terutama terjadinya demoralisasi kehidupan bersama sebagai akibat tererosinya nilai-nilai tradisi oleh proses modernisasi dan globalisasi. Kalau masyarakat dan bangsa Indonesia pada saat ini menghadapi masalah demoralisasi, krisis jati diri dan kepribadian, sebagai ekses dari derasnya arus perubahan dan globalisasi yang masuk ke Indonesia, maka aktualisasi dan kontekstualisasi ajaran moral Sosrokartono diharapkan mampu menangkal ekses globalisasi tersebut. Ajaran moral Sosrokartono sarat kandungan nilai ñkepedulian sosialò sehingga apabila ajaran moral 
HUMANIKA Vol. 19 No. 1 (2014) ISSN 1412-9418

Binner Ethical Ajaran Sosrokartono

Mulyono

tersebut benar-benar dilaksanakan oleh manusia Indonesia maka sifat manusia yang individu-alistis, matarialistis dan sekularistis dapat dikendalikan. Masyarakat Indonesia yang mempunyai kepe-dulian sosial tinggi (caring society) dapat ditegakkan kembali.

Ajaran moral Sosrokartono yang berbentuk binner etik memang perlu dipahami maknanya melalui segenap penafsiran berdasarkan kemampuan akal, indera, dan rasa-pangrasa penulis. Metode hermeneutik niscaya digunakan penulis, karena penulis memang tidak punya akses secara langsung dengan Sosro-kartono akibat terpisahnya ruang, waktu dan tradisi. Kalau Sosrokartono mengekspresikan ajaran moralnya dalam bahasa teks sehingga ada makna subjektif, maka penulis berusaha membawa ke luar makna subyektif sebagai ekspresi obyektif kepada pembaca atau orang lain. Bahkan dengan perspektif hermeneutika, penulis berusaha mengungkapkan horizon masa lalu kepada dunia masa kini. Pemberian makna ajaran moral Sosrokartono sama artinya dengan memahamkan (Verstehen) ajaran moral Sosrokartono kepada para pembaca.

\section{METODE}

Penelitian ini adalah penelitian pustaka. Oleh karenanya metode penelitian yang digunakan tentu saja metode kualitatif. Sedangkan unsur metodis yang digunakan oleh peneliti yakni, pertama adalah interpretasi.
Cara ini digunakan penulis untuk menerangkan dan mengungkapkan makna dari ajaran moral Sosrokartono. Kedua adalah cara analisis abstraksi. Cara ini digunakan penulis untuk menemukan unsur-unsur penting dan hakiki dari ajaran moral Sosrokartono yang berbentuk binner etik.Ketiga adalah verstehen. Cara ini digunakan oleh penulis untuk mencari pemahaman yang mendalam dari ajaran moral Sosrokartono yang berbetuk binner etichaldalam konteks menemukan relevansinya terhadap permasalahan yang berkembang dalam kehidupan masyarakat masa kini.

\section{PEMBAHASAN}

Sosrokartono sering menyampaikan mutiara-mutiara kata sebagai dalil ajaran moralnya dengan menggunakan logika paradoksal, sehingga ajaran itu tidak bisa dipahami secara baik dengan hanya mengunakan kemampuan indera dan akal belaka namun harus mengunakan pula rasapangrasa. Sosrokartono memang mengemukakan beberapa ajarannya dalam bentuk binner opposition, yaitu dua kata yang saling berlawanan. Dua kata yang ber-lawanan ini dicoba dipadukan dengan memasukkan citra positif ke dalam citra negatif, agar supaya citra negatif terkontaminasi citra positif, sehingga yang tampak dan dirasakan oleh indera adalah cita positifnya (Khakim, 2008: 106). 
Mutiara-mutiara kata yang bersifat paradoksal dari Sosrokartono adalah:

"Sugih tanpo bondo, Digddoyo tanpo aji, Ngluruk tanpo bala, Menang tanpo ngasorake"(PA.Koesno, 1954: 38 $-41)$.

Artinya:

ñKaya tanpa harta, sakti tanpa jimat, bertempur tanpa pasukan atau balatentaras, menang tanpa merendahkanò.

\section{Dari ajaran Sosrokartono} tersebut dapatlah ditafsirkan bahwa manusia linuwih atau unggul bukanlah manusia yang banyak harta, tetapi manusia yang peduli terhadap nasib sesama, yakni manusia yang selalu berupaya menolong sesamanya, baik dengan tenaga, pikiran, maupun dengan harta. Bagi Sosrokartono, yang terpenting dalam kehidupan manusia adalah kedamaian jiwa. Jiwa harus diisi dengan kekuatan-kekuatan alamiah, seperti makna sebuah perjuangan, kebenaran, kejujuran, kebersamaan, dan makna kasih sayang di antara sesama makhluk Tuhan. Untuk menjadi manusia unggul, seseorang dituntut agar senantiasa mengabdikan diri kepada sesama hamba Tuhan, serta tidak mengukur keutamaan manusia pada kekuasaan dan kekayaan harta benda. Dengan prinsip "leladi mring sesami" sebagai manifestasi berbakti kepada Tuhan, maka terkandung keyakinan bahwa manusia tidak hanya hidup di dunia ini namun juga hidup di dunia akherat. Oleh karena itu, manusia tidak selayaknya hanya berorientasi pada kehidupan di dunia (sekuler) namun harus mempersiapkan kehidupan di dunia akhirat nantinya.

Sosrokartono mengajarkan bahwa setiap manusia mendambakan kebahagiaan dan ketenteraman hidup. Kedua dambaan itu tak dapat diwujudkan dengan modal kaya harta benda, kekuasaan dan dukungan banyak orang. Namun kedua dambaan tersebut dapat diwujudkan dengan kekayaan hati dan mental yang diimplementasikan oleh laku leladi mring sesami dan berbuat tanpa pamrih. Bahkan dengan mengendalikan nafsu kebendaan duniawi yang sering menciptakan penderitaan dapatlah berbuah keadaan damai sejati yang kekal.

Dengan ajaran "sugih tanpa bandha, digdaya tanpa aji, nglurug tanpa bala, dan menang tanpa ngasorake" memperlihatkan dengan jelas bahwa Sosrokartono sangat menekankan dan mementingkan kekuatan batin (jiwa) dan sikap batin yang tepat dalam menjalani hidup bersama orang lain di alam dunia. Sosrokartono tidak mementingkan kemampuan dan kekuatan materi (fisik). Oleh karenanya, untuk memahami ajaran Sosrokartono ini haruslah ditangkap dengan 'rasapangrasa' bukan dengan akal dan indera. Dalam konteks ajaran tersebut dapat ditafsirkan bahwa orang yang kaya (sugih) tidak harus berlimpah 
HUMANIKA Vol. 19 No. 1 (2014) ISSN 1412-9418

Binner Ethical Ajaran Sosrokartono

Mulyono

harta, melainkan orang yang merasa cukup dan selalu memberi dan membantu (menolong) orang lain, leladi mring sesami. Orang yang sakti (digdaya), sehingga disegani dan dihormati banyak orang, tidak harus punya jimat, senjata ataupun kekuatan fisik, melainkan orang yang banyak menolong atau membantu orang lain. Selanjutnya orang yang bertempur (nglurug) tidak harus mengerahkan pasukan (bala), melainkan dengan melalui kekuatan batinnya orang dapat berkarya dengan tangannya sendiri tanpa minta pertolongan dan bantuan orang lain, karena musuh sesungguhnya dari manusia itu adalah setan yang ada dalam dirinya sendiri (Khakim, 2008: 71). Demikian pula orang yang menang dalam perang atau persaingan tidak harus merendahkan harga diri orang yang terkalahkan. Sikap batin yang tepat adalah bahwa kemenangan seharusnya diraih dengan jalan damai, tidak dengan jalan kekerasan dan tanpa membuat lawan malu dan terhina.

"Ngupadosi: padang ing peteng, seneng ing sengsara, tunggaling sewu yuta"(Syuropati, 2011: 125).

Artinya:

ñMencari: terang di dalam gelap, senang di dalam sengsara, ribuan juta contohnyaò.
Ungkapan tersebut merupakan niat dan tujuan praksis kehidupan Sosrokartono yang berusaha untuk mengubah suasana yang gelap menjadi terang, merubah yang sengsara menjadi senang. Sosrokartono se-akan mengikuti jejak para nabi dalam menerangi kegelapan umat. Namun Sosrokartono hanya berusaha mengentaskan kesengsaraan masyarakat dari penyakit medis dan penyakit hati menuju kesembuhan dan kebahagiaan pada umumnya (Khakim 2008: 105).

Dari ungkapan tersebut tersembunyi ajaran moral: ñJika anda temukan kegelapan, maka terangilah. Jika anda temukan kesengsaraan di manapun, maka berikanlah kesenangan. Berjuta-juta orang membutuhkan cahaya terang, pertolongan, dan sinar kebahagiaanò Sosrokartono menunjuk-kan juga adanya hikmah atau dimensi tersembunyi dari setiap kejadian atau keadaan. Menurut Sosrokartono, apa saja yang ada di dunia ini adalah relatif, sehingga tidak ada kesenangan, kesengsaraan, kegelapan, maupun kecerahan yang abadi. Setelah kesulitan pastilah ada kemudahan.

"Angelar Pemandeng Tegesipun Angringkes Pemantheng; Ambuka Netra Tegesipun Anutup Netra; Anggukup Kabeh Tegesipun Anyandak Siji" (Surat Sosrokartono dari Binjei, 12 November 1931).

Artinya:

ñMeluaskan pandangan berarti memusatkan perhatian atau fokus pada sesuatu. Membuka mata 
berarti menutup penglihatan. Mencakup semuanya berarti memegang atau berpegangan pada yang satuò

\section{Sosrokartono mengajarkan bahwa meluaskan pandangan ber- makna melampaui diri-sendiri dan memandang sesama manusia, umat manusia seluruhnya, yang berarti manusia meninggalkan sifatnya yang serba sendiri atau egois. Namun karena manusia asal dan tujuannya sama, maka meluaskan pemandang-an berarti memusatkan perhatian sepenuhnya pada ñYang Satuò, yaitu Tuhan Yang} Maha Esa (Ali, 1966: 69).

Sosrokartono menekankan juga perlunya memperluas kesadaran untuk melepaskan diri dari fokus atau keterikatan. Setelah seseorang melihat sebanyak-banyaknya, belajar sebanyak-banyaknya, berpikir sebanyak-banyaknya, mendapatkan pengetahuan dan pengalaman seba-nyakbanyaknya, maka ia mem-punyai pandangan yang luas dan tidak picik. Berdasarkan pandangan yang luas itu akhirnya seseorang harus ngringkes atau fokus hanya pada ñcatur murtiò, yaitu menyatu-kan empat unsur (Pikiran, Perasaan, Perkataan, dan Perbuatan) menjadi satu kesatuan. Laku catur murti ini tak dapat dilepaskan dari dasar melayani dan mengabdi kepada Tuhan Yang Maha Esa (Aksan, 1988:89).

ñAmbuka netra tegesipun anutup netraò mengandung makna ajaran agar orang seharusnya membuka mata, melihat dan menyaksikan kesusahan dan penderitaaan orang lain kemudian ikhlas melakukan bantuan dan pertolongan kepada mereka. Di sisi lain orang seharusnya menutup mata terhadap kepentingan pribadi. Menyisihkan kepentingan pribadi dan mendahulukan kepentingan mereka yang menderita dan memerlukan pertolongan.Ajaran tersebut dapat ditafsirkan pula bahwa membuka mata apabila mengabdi dan membantu sesama manusia, dan menutup mata terhadap sifat-sifat lahiriah yang membeda-bedakan sesama manusia, "Angukup Kabeh, tegesipun Anyandak Siji” (Ali, 1966: 51), artinya mencakup semua berarti me-megang satu.Substansi dari ajaran ini adalah bahwa Sosrokartono menjunjung tinggi martabat dan derajat sesama manusia, sehingga ia tidak membeda-bedakan diri dari sesama manusia. Seluruh umat manusia dicakup dalam satu kesadaran tentang kemanusiaan. P.A.Roesno (1954: 14) menafsirkan bahwa apabila manusia melayani atau menolong sesama manusia (tanpa pandang bulu), maka berarti mengabdi atau berbakti kepada ñYang Satuò (Tuhan Yang Maha Esa). Mengabdi kepada sesama manusia berarti berbakti kepada ñYang Satuò. R. Mohammad Ali (1966: 69) memberikan tafsir bahwa mencakup semuanya jelas dalam membaktikan diri kepada sesama hidup dengan tekad-asih, bukan tekad-pamrih. Setiap orang yang menderita dan memerlukan pertolongan seharusnya diterima dan dilayani dengan kasih sayang. Pada 
HUMANIKA Vol. 19 No. 1 (2014) ISSN 1412-9418

Binner Ethical Ajaran Sosrokartono

Mulyono

hakikatnya, dengan mencakup semua

abdi-abdi Tuhan, yang dicakup sebenarnya ñYang Satuò atau Tuhan Yang Maha Esa.

Prinsip moral mutiara kata tersebut berimplikasi bahwa apabila seseorang mampu mencakup umat manusia seluruhnya dalam satu gerak kasih-sayang, berarti berhasil mencakup ñYang Satuò, Tuhan Yang Maha Esa. Sebaliknya apabila seseorang sudah berhasil mencakup ñYang Satuò maka gerak lakunya penuh kasih sayang kepada sesama manusia, leladi mring sesami. Sosrokartono dalam perilaku hidup kesehariannya selalu melayani dan memberikan pertotolongan kepada semua orang tanpa pandang bulu seperti orangorang miskin, orang-orang rendahan, rakyat jelata, orang-orang yang membutuhkan pertolong-an, orangorang yang sakit, yang menderita, orang-orang atasan atau bawahan, orang-orang yang kesepian atau menyendiri dalam hidup karena tekanan batin, orang-orang hina. Sosrokartono melayani dan mengabdi kepada mereka dengan penuh kasih, karena mengabdi kepada mereka sesunguhnya sama dengan mengabdi dan memuja Tuhan Yang Maha Esa (Aksan, 1988: 87). Sosrokartono juga memberikan ajaran bahwa kesadaran yang merangkul seluruh alam semesta dengan berpegang pada ñGusti dalam diriò atau mengembangkan kasih di dalam diri dan menyebarkannya ke seluruh alam semesta.
"Durung Menang yen Durung Wani

Kalah; Durung Unggul yen Durung

Wani Asor; Durung Gede yen

Durung Wani Cilik" (Surat

Sosrokartono dari Binjei, 12

November 1931).

Artinya:

ñBelum menang kalau belum berani kalah. Belum unggul kalau belum berani rendah. Belum besar kalau belum berani kecilò.

Substansi dari ajaran moral Sosrokartono ini adalah agar manusia rendah hati dan berjiwa besar. Sosrokartono juga menasehati agar manusia dapat menundukkan ego, karena orang yang egois, yang membesarkan dirinya sebenarnya berjiwa kecil, sehingga malu mengakui dirinya kecil. Kerendahan hati adalah buah kesadaran. Menurut penafsiran Mohammad A. Syuropati (2011: 96), ungkapan tersebut merupakan bagian dari jatuh bangunnya sebuah kesuksesan. Artinya, di balik kemenangan ada kekalahan, di balik kemuliaan ada kehinaan, di balik kebesaran ada masa-masa yang mengecilkan dan mengucilkan. Dengan memahami dan menghayati kenyataan ini, maka Sosrokartono lebih memilih jalan kehidupan agar selamat, damai, dan bahagia dengan prinsip tersebut. Cara berjalan di jalan ini diyakini benar dan diridhoi Allah. 
R. Mohammad Ali (1966: 70) menafsirkan ajaran tersebut sebagai ilmu pengabdian pribadi dengan lakunya tidak melenyapkan pribadi manusia itu sendiri, sehingga solaholah manusia menjadi budak sesama hidup. Mengabdi kepada sesama manusia adalah pengabdian kepada Tuhan Yang Maha Esa, sehingga dalam pengabdian itu segala derita harus dijalani dengan tabah, tawakal, dan dengan hati teguh. Namun keyakinan menang, unggul, dan gede senantiasa juga berarti kalah, asor, dan cilik, karena dihadapan Tuhan Yang Maha Esa menang-kalah, unggul-asor, dan gede-cilik itu tidak ada. Soediani (dalam Paguyuban ñSOSROKARTANANò, 1987: 15) menerangkan bahwa menurut Sosrokartono apabila manusia sudah angukup kabeh dan anyandak siji dalam lakunya ternyata belum cukup. Manusia harus menambah kehati-hatian, sebab durung menang yen durung wani kalah, durung unggul yen durung wani asor, durung gede yen durung ngaku cilik. Kata ñwaniò dalam suratnya diganti ñngakuò. Pengantian kata ini tepat sekali. Manusia memang harus berendah hati agar tidak tersesat dan terjatuh bukan karena tersandung gunung tetapi tersandung kerikil.

\section{SIMPULAN}

Ajaran moral Sosrokartono yang berbentuk binner etichal bisa dipahami dengan memberikan interpretasi melalui perenungan yang mendalam dan pengunaan rasa-pangrasa manusia. Makna dari ajaran moral Sosrokartono yang berbentuk binner etik tersebut ada dalam bingkai sikap dan perilaku Sosrokartono, yang selalu ingin berbakti dan menghambakan diri kepada Tuhan melalui perilaku menolong dan membantu sesama manusia yang membutuhkan dengan tanpa pamrih berdasar pada prinsip leladi mring sesami.

Benang merah dari semua ajaran moral Sosrokartono adalah mementing-kan kekuatan batin atau jiwa, sehingga ajaran moral Sosrokartono sangat relevan: di satu sisi, untuk mengen-dalikan dan menangkal berkembangnya budaya dan perilaku yang materialistis, individualistis, pragmatis, hedonistis dan sekularisitik. Di sisi lain, untuk mengembangkan kepedulian sosial (social caring). Ajaran moral Sosrokartono menggugah kesadaran manusia akan tanggung jawabnya sebagai warga dalam kehidupan bersama dalam segala dimensinya. Ajaran moral Sosrokartono juga mengajak manusia untuk tidak hanya melihat segala sesuatu dan bertindak dalam kerangka kepentingan dirinya sendiri, melainkan setiap manusia harus mempedulikan kepentingan bersama, kesejahteraan dan kebahagiaan bersama.

Ajaran moral Sosrokartono sangat relevan bagi upaya menangkal tererosinya kepribadian atau karakter bangsa Indonesia sebagai dampak 
modernisasi dan globalisasi. Oleh karena itu, kearifan lokal semacam ini perlu digali kembali, diaktuali-sasikan dan dikembangkan bagi upaya memajukan kehidupan bangsa Indonesia dengan tetap bertumpu pada kepribadiannya sendiri. Bangsa Indonesia perlu mengingat kembali doktrin Tri Sakti dari Bung Karno yang menginginkan bangsa Indonesia berdaulat dalam bidang politik, berdiri di atas kaki sendiri dalam bidang ekonomi, serta berkepribadian dalam bidang budaya.

\section{DAFTAR PUSTAKA}

Adeney, Bernard T. (2000). Etika Sosial Lintas Budaya. Yogyakarta: Penerbit Kanisius. Adisasmita, Sumidi. (1968). Ichtisar

Riwayat Hidup dan

Perikehidupan Maha Putra

Indonesia Drs. R.M.P. Sosro-

kartono 1877-1952. Yogyakarta: Kaelan. (2005). Metode Penelitian

Kualitatif Bidang Filsafat.

Yogyakarta: Penerbit Paradigma.

Keraf, A.Sonny. (1991). Etika Bisnis:

Membangun Citra Bisnis sebagai Profesi Luhur. Yogyakarta: Penerbit Kanisius.

Khakim, Indy G. (2008). Sugih Tanpa

Bandha, Tafsir Surat-surat \& Mutiara-Mutiara Drs. R.M.P. Sosrokartono. Blora: Pustaka Kaona.
Yayasan Sosrokartono Yogyakarta.

Aksan. (1985). Ilmu dan Laku Drs. R.M.P. Sosrokartono. Surabaya: Citra Jaya Murti.

. (tt.). Sahabat Bung Karno yang Besar Drs. R.M.P. Sosrokartono Putra Indonesia yang Besar.

Ali, R.Mohammad. (1966). Ilmu Kantong Bolong, Ilmu Kantong Kosong, Ilmu Sunyi Drs. R.M.P. Sosrokartono: Suatu Tanggapan. Panitia Penyusunan Buku Riwayat Drs. R.M.P. Sosro-kartono, Jakarta.

Bertens, K. (2005). Etika (cet. ke-9). Jakarta: PT Gramedia Pustaka Utama.

Ciptoprawiro, Abdullah. (1986). Filsafat Jawa. Jakarta: Balai Pustaka.

De Jonge. (1976). Salah Satu Sikap Hidup Orang Jawa. Yogyakarta: Kanisius.

Machfoeld, Musa al. (1976). Priagung Darus-Us-Salam Almarhum Drs. Sosrokartono di Jalan Poengkoer no. 7 Bandung. Yayasan Sosrokartono, Yogyakarta.

Magnis, Frans Von. (1979). Etika Umum. Yogyakarta: Penerbitan Yayasan Kanisius.

Magnis-Suseno, Franz. (1987). Etika

Dasar (Masalah-masalah Pokok Filsafat Moral). Yogyakarta: Penerbit Kanius. 
(1999). Etika

Jawa: Sebuah Analisa Falsafi tentang Kebijaksanaan Hidup

Jawa. Jakarta: PT Gramedia Pustaka Utama.

Mulder, Niels. (1983). Kebatinan dan Sikap Hidup Sehari-hari Orang Jawa. Jakarta: Gramedia.

Popkin, Richard \& Stroll, Avrum. (1958). Philosophy Made Simple. New York: Made Simple Books Inc.

Roesno. (1954). Karena Panggilan Ibu Sedjati: Riwayat Hidup dari Drs. R.M.P. Sosrokartono. Jakarta: Panitia Buku Peringatan R.M.P. Sosrokartono.
Salam, Solichin. (1987). R.M.P. Sosrokartono: Sebuah Biografi. Jakarta: Yayasan Sosrokartono Jakarta.

Sastrapratedja, M. (2012). ก̃́Lima Gagasan yang Dapat Mengubah Negara dan Bangsa Indonesiaò. Makalah pada Seminar Nasional Penguatan Pilar-Pilar Berbangsa dan Bernegara sebagai Kesiapan Eksistensial menuju Kejayaan Masa Depan Indonesia. Semarang, 29 September 2012.

Tridjana. (tt.). Adjaran-Adjaran Almarhum Drs. R.M.P. Sosrokartono 1877-1952. Yogyakarta: Yayasan Sosrokartono Yogyakarta. 